\title{
Analysis of Dipole Antenna Printed on Thin Film by Using Electromagnetic Simulators
}

\author{
Mitsuo TAGUCHI* Yuki MATSUNAGA \\ Dept. of Electrical \& Electronic Eng., Nagasaki University \\ 1-14 Bunkyo-machi, Nagasaki-shi, 852-8521 Japan \\ E-mail:*mtaguchi@net.nagasaki-u.ac.jp
}

\begin{abstract}
The printed dipole antenna on thin polyimide film is calculated by using WIPL-D and IE3D based on the method of moment, Micro-Stripes based on TLM method. Its input impedance characteristics are compared with measured data and discussed.
\end{abstract}

Keywords: printed antenna, method of moment, WIPL-D, FDTD method. TLM method

\section{Introduction}

With the development of numerical analysis method, the many kind of electromagnetic simulators are used for the analysis of antennas. Authors have calculated the dipole antenna, the linear polarized rectangular patch microstrip antenna, the circular polarized rectangular patch microstrip antenna by using the electromagnetic simulators based on the method of moment, the FDTD method and the TLM (Transmission Line Matrix) method [1]-[4]. The calculated antenna characteristics such as the input impedance, the radiation pattern, and the directivity are compared with the measured results. The features of simulators are also discussed.

Recently small antennas printed on the thin dielectric film are used for the radio frequency identification (RFID) applications [5], [6]. The FDTD method is a powerful tool for analyzing the antenna including conducting and dielectric materials. However, the numerical calculation of the antenna on thin film is time consuming, because the maximum cell size is limited to be less than about ten times of the minimum cell size in the FDTD method.

In this paper the dipole antenna printed on the polyimide film is numerically and experimentally analyzed. The input impedance of this antenna is calculated by using the electromagnetic simulators WIPL-D and IE3D based on the method of moment and Micro-Stripes based on the TLM method [7]-[9].

\section{Analytical model and numerical results}

Figure 1 shows the dipole antenna printed on the polyimide film. The dipole antenna of thickness $35 \mu \mathrm{m}$ is printed on the thin film of thickness $95 \mu \mathrm{m}$. The antenna is covered by the film of thickness $50 \mu \mathrm{m}$ for protection. The relative dielectric constant of film is 3.5. In this paper, following two antennas are analyzed. Antenna No.1: $\mathrm{L}=64.8 \mathrm{~mm}$ and $\mathrm{d}=24 \mathrm{~mm}$ and Antenna No.2: $\mathrm{L}=88 \mathrm{~mm}$ and $\mathrm{d}=38 \mathrm{~mm}$.

In the numerical calculation by WIPL-D, the upper and lower films are modeled as the rectangular parallelepiped with thickness $95 \mu \mathrm{m}$ and $50 \mu \mathrm{m}$, respectively. The thickness of antenna element is assumed to be infinitely thin. Figure 2 shows the geometrical model of 
printed antenna. The total number of unknown electric and magnetic currents of Antenna No.1 are 183 and 134, respectively. Figure 3 shows the edge cell and feed wire of antenna. Two planar monopole elements are connected by the thin wire with radius of $1 \mu \mathrm{m}$.

In the numerical calculation by Micro-Stripes, the antenna is mounted on the ground plane in the xy plane. The antenna is located in the zx plane. The calculation region is $460 \mathrm{~mm}$ by 460 $\mathrm{mm}$ ( $\mathrm{x}$ and $\mathrm{y}$ direction) by $312 \mathrm{~mm}$ ( $\mathrm{z}$ direction). The minimum cell size in the calculation by Micro-Stripes is $0.25 \mathrm{~mm}$ in $\mathrm{x}$ direction, $0.015 \mathrm{~mm}$ in y direction and $0.8 \mathrm{~mm}$ in $\mathrm{z}$ direction. The maximum cell size is $11.5 \mathrm{~mm}$ in $\mathrm{x}$ and $\mathrm{z}$ direction and $11.4 \mathrm{~mm}$ in $\mathrm{y}$ direction. Figure 4 shows the calculation model in Micro-Stripes.

In the numerical calculation by IE3D, the infinite film is assumed. The thickness of antenna is assumed to be infinitely thin. The cell size in the highest frequency is $1 / 30$ wavelength and the width of edge cell is $0.39 \mathrm{~mm}$. Figure 5 shows the edge cell and the feed port in IE3D.

In the measurement of input impedance, the antenna is mounted on the ground plane of $1.6 \mathrm{~m}$ by $1.6 \mathrm{~m}$.

Figure 6 and 7 shows the input impedance characteristics of Antenna No.1 and No.2, respectively. The anti-resonant frequency of the antenna No.1 calculated by IE3D is higher than that of measured data. This may be due to the fact that the width of film is narrow.

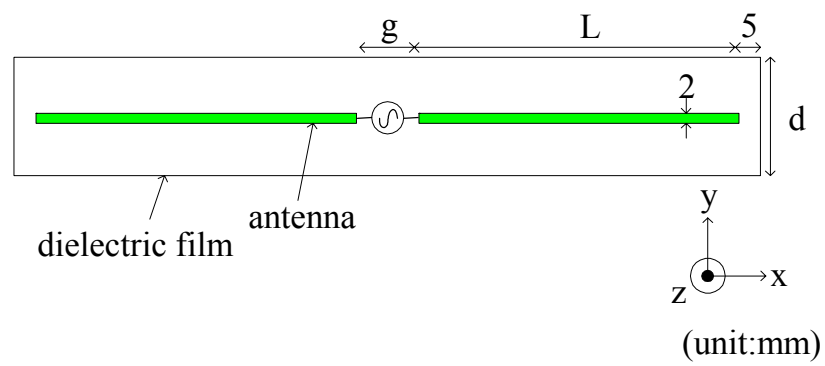

(a) top view

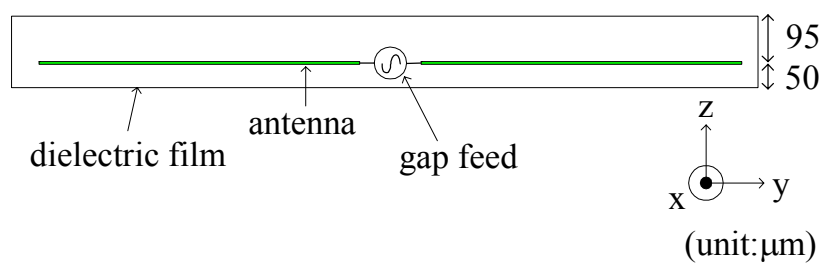

(b) cross sectional view

Figure 1 Dipole antenna printed on polyimide film.

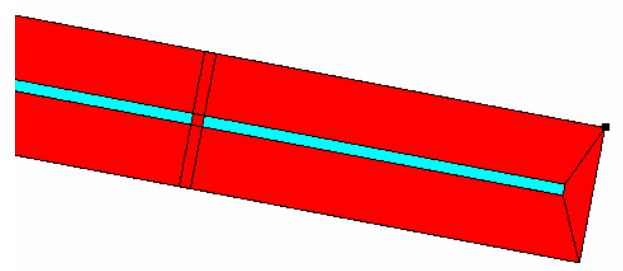

Figure 2 Geometrical model in WIPL-D.

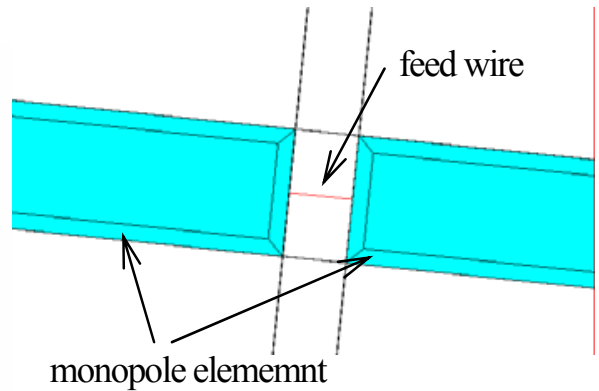

Figure 3 Edge cell and feed wire in WIPL-D. 


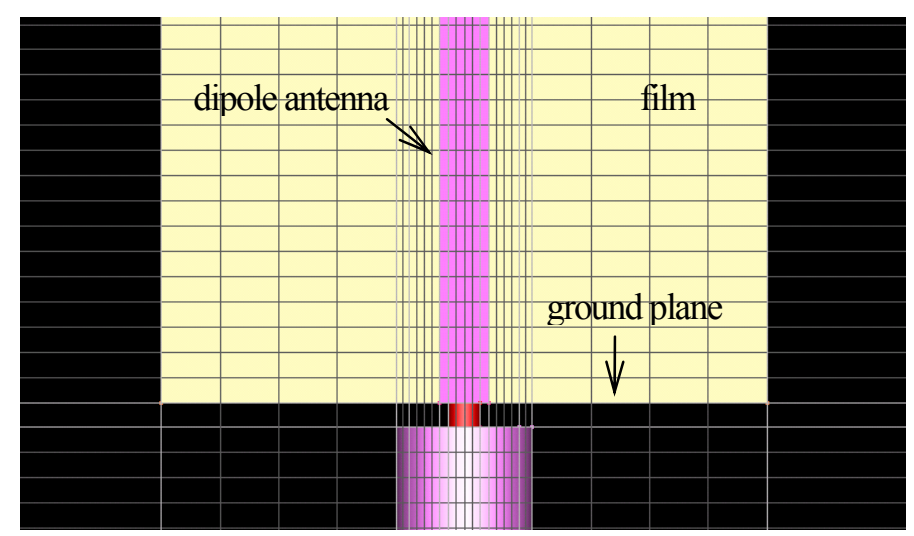

Figure 4 Modeling of antenna in Micro-Stripes

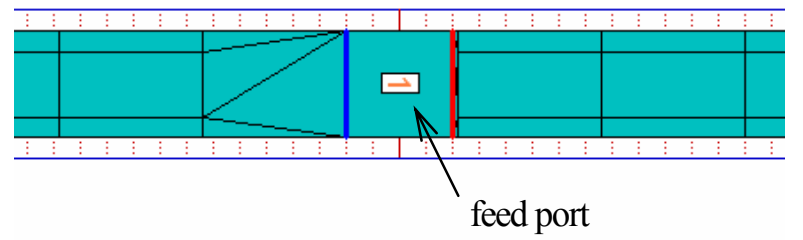

Figure 5 Edge cell and feed port in IE3D

\section{Conclusion}

The dipole antenna printed on the polyimide film is calculated by using WIPL-D, IE3D and Micro-Stripes. The design of small tag antenna composed of multilayer conductors on thin film for the RFID application will be presented in the next opportunity.

\section{References}

[1] M. Taguchi, T. Fujimoto and K. Tanaka: "Comparison of numerical solutions of hollow cylindrical dipole antennas", Proc. of $18^{\text {th }}$ Annual Review of Progress in Applied Computational Electromagnetics, pp. 595-600, March 2002.

[2] M. Taguchi, K. Ichikawa and K. Tanaka: "Numerical analysis of microstrip antenna by using electromagnetic simulators", Proc. of $20^{\text {th }}$ Annual Review of Progress in Applied Computational Electromagnetics, April 2004.

[3] M. Taguchi, H. Morishita, M. Hirose and M. Haneishi: "Analysis of rectangular microstrip antenna for circular polarization by using electromagnetic simulators", Technical Report of IEICE, AP2001-185, Jan. 2002 (in Japanese).

[4] M. Taguchi, K. Ichikawa, H. Morishita, T. Tanaka, M. Hirose and T. Ishizone, "Numerical analysis of microstrip antenna by using electromagnetic simulators -Part 3-", Technical Report of IEICE, MST2004-03, Septt. 2004 (in Japanese).

[5] K. Finkenzeller: "RFID handbook”, John Wiley \& Sons, 2003.

[6] C. Cho, H. Choo and I. Park: "Design of small tag antennas for RFID application", 2004 Korea-Japan Joint Conference on AP/EMC/EMT, pp.27-31, Nov. 2004.

[7] "WIPL-D Pro v5.1 User's Manual”, WIPL Ltd., 2004.

[8] "Micro-Stripes Reference Manual, Release 6.0”, Flomerics Ltd., 2002. 
[9] “IE3D User’s Manual Release 7”, Zeland Software Inc., Dec. 1999.
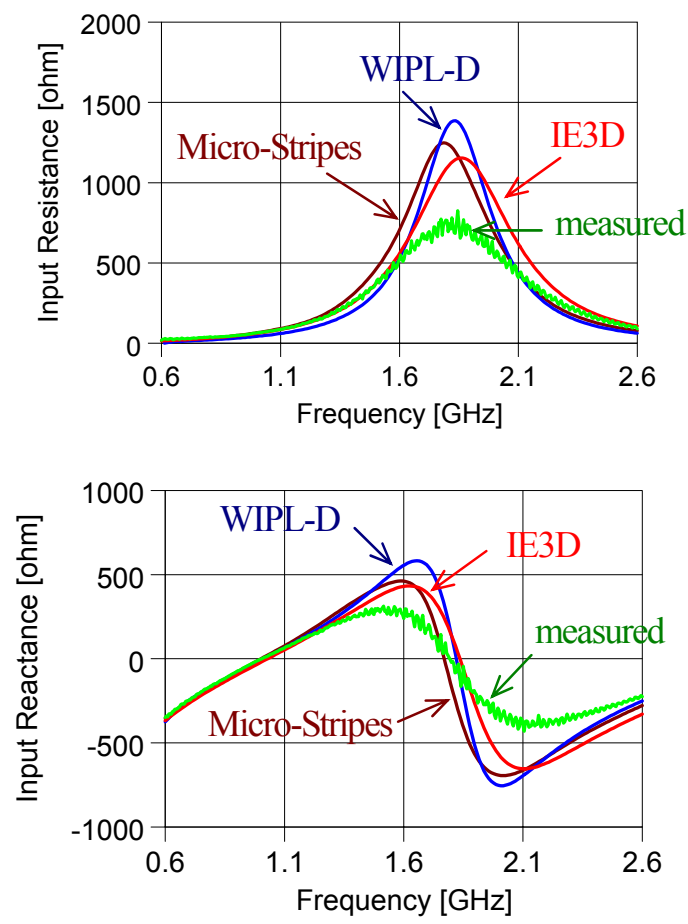

Figure $6 \quad$ Input impedance of antenna No.1. $\mathrm{L}=64.8 \mathrm{~mm}, \mathrm{~d}=24 \mathrm{~mm}, \mathrm{~g}=2 \mathrm{~mm}$
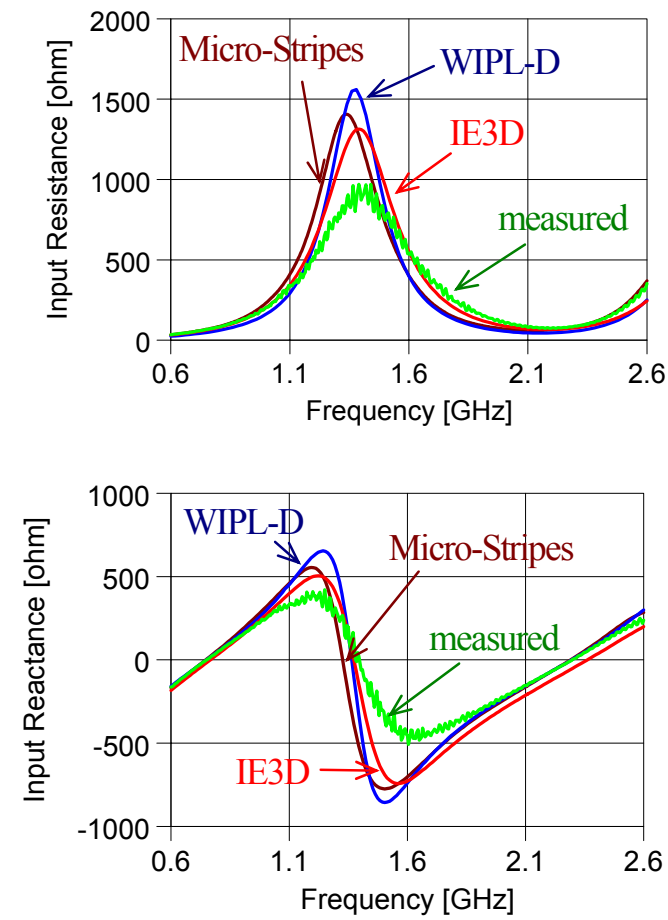

Figure 7 Input impedance of antenna No.2. $\mathrm{L}=88 \mathrm{~mm}, \mathrm{~d}=38 \mathrm{~mm}, \mathrm{~g}=2 \mathrm{~mm}$ 